\title{
Modelling size-at-age in wild immature female octopus: a bioenergetics approach
}

\author{
Jessica André ${ }^{1, *}$, Gretta T. Pecl ${ }^{1}$, Eric P. M. Grist ${ }^{2}$, Jayson M. Semmens ${ }^{1}$, \\ Malcolm Haddon ${ }^{3}$, Stephen C. Leporati ${ }^{1}$ \\ ${ }^{1}$ Tasmanian Aquaculture and Fisheries Institute, Marine Research Laboratories, University of Tasmania, Private Bag 49, \\ Hobart, Tasmania 7001, Australia \\ ${ }^{2}$ Environmental Research Institute, North Highland College, UHI Millenium Institute, Castle Street, Thurso, \\ Caithness KW14 7JD, UK \\ ${ }^{3}$ CSIRO Marine \& Atmospheric Research, Castray Esplanade, Hobart, Tasmania 7000, Australia
}

\begin{abstract}
The population dynamics of cephalopods are poorly understood because intra-specific size-at-age is characteristically variable. Much of the variation observed is attributed to temperature and food, but other generally overlooked factors such as hatchling size and inherent growth capacities also affect size-at-age. In the present paper, we investigated the relative influence of the principal abiotic (environmental temperature) and biotic (food consumption, hatchling size, inherent growth capacity) factors affecting size-at-age in immature octopus. Using a bioenergetics model and size-at-age data of wild-caught immature Octopus pallidus, we simulated the juvenile growth trajectories of individuals hatched in different seasons (summer, autumn and winter) based on food availability, metabolism, environmental temperature and individual variability, under an assumption of 2phase growth. Simulations predict that the effect of hatchling size on size-at-age was secondary to that of inherent growth capacity. Projections suggest that wild immature populations comprise a mixture of individuals displaying exponential growth and 2-phase growth and that the proportion of each depends primarily on the individuals' inherent growth capacities and food availability. High food intake was projected to decrease the number of individuals displaying 2-phase growth by delaying the transition between the 2 growth phases, resulting in larger individuals. Overall, individuals hatched in summer grew to larger sizes and matured earlier than individuals hatched in autumn or winter, independent of food availability. The size-at-age distribution of the summer and autumn cohorts tended to become bimodal under certain food intake levels, which highlights the importance of coupling size data with accurate age estimates in future octopus population studies.
\end{abstract}

KEY WORDS: Early life history $\cdot$ Energy balance $\cdot$ Individual-based model $\cdot$ Pale octopus

\section{INTRODUCTION}

Individual variability in growth has been observed in many taxa, including cephalopods (Domain et al. 2000), gastropods (Hughes \& Roberts 1980) and teleosts (Searcy \& Sponaugle 2000), resulting in intraspecific size-at-age data often being highly variable (Challier et al. 2006). Under these conditions, understanding population dynamics and changes in population size structure becomes challenging (Gurney \& Veitch 2007), especially for exploited species. In cephalopods, growth rates are mainly governed by nutrition, body size, water temperature and, later in the life cycle, the energy diverted towards reproduction (Semmens et al. 2004). Both the quantity (Jackson \& Moltschaniwskyj 2001, Villanueva et al. 2002) and quality (Segawa 1990, Iglesias et al. 2004) of food influence growth, with prey high in protein and low in lipid providing the highest growth rates (Segawa 1993, Lee 1994, García García \& Aguado Giménez 2002). Water temperature is also of critical importance in defining cephalopod developmental rates, and there has been 
much emphasis on examining the effects of temperature on growth and its implications for size-at-age (see Forsythe \& Van Heukelem 1987, Forsythe 2004; and Semmens et al. 2004 for a review). A key hypothesis that emerged from this research is the 'Forsythe effect' (Forsythe 1993, 2004), which states that when hatching occurs over a period of continually warming days (and hence warming water temperatures), each microcohort of hatchlings will grow significantly faster than micro-cohort(s) hatched only weeks previously. This hypothesis is supported by evidence from both laboratory (Villanueva 2000, Hatfield et al. 2001, Leporati et al. 2007) and field studies (Jackson et al. 1997, Hatfield 2000, Jackson \& Moltschaniwskyj 2002), making seasonal temperature, along with nutrition, the 2 most important factors contributing to variations in size-atage in natural populations.

Other generally overlooked factors, such as hatchling size (Pecl et al. 2004a, Leporati et al. 2007), can also affect size-at-age. Within a species, hatchling size is known to vary by at least $147 \%$ in squid (e.g. Sepioteuthis australis; Pecl et al. 2004a) and 239\% in cuttlefish (e.g. Sepia officinalis; Domingues et al. 2001). Most cephalopods are believed to follow a 2-phase growth pattern, starting with a rapid exponential phase followed by a slower second growth phase, often represented by a power function (Semmens et al. 2004, Boyle \& Rodhouse 2005). Given this growth pattern, differences between individuals at hatching can amplify throughout the lifespan (Pecl et al. 2004a) and have an impact on size-at-age. Hatchling size variation has multiple origins that can be divided into environmental effects, maternal effects and genetic effects. The direct effect of temperature on hatchling size is well known (Boletzky 1994), with higher incubation temperatures resulting in faster embryonic development and hence smaller hatchlings and, conversely, lower incubation temperatures resulting in slower development and larger hatchlings. Maternal condition during oogenesis can also introduce variation in intra-specific hatchling size, as hatchling size is positively correlated with maternal nutrition in several species (e.g. Octopus vulgaris; Sakaguchi et al. 2002 and Euprymna tasmanica; Steer et al. 2004). Genetic differences may also be a source of hatchling size variation. Multiple paternities within broods have been demonstrated for some cuttlefish (Naud et al. 2004) and squid (Shaw \& Boyle 1997, Buresch et al. 2001) species, and difference in paternity has been linked to a difference in hatchling size (Loligo forbesi; Emery et al. 2001).

Another potential source of individual variability in size-at-age is inherent growth plasticity (Forsythe \& Van Heukelem 1987, Boyle \& von Boletzky 1996). Genotype is known to have a significant effect on physiological rates in molluscs, particularly on growth rate (Koehn 1991). Phenotypic plasticity, where a single genotype produces different phenotypes as a result of environmental conditions, also appears to play an important role in the variability observed in cephalopods (Boyle \& von Boletzky 1996).

Different combinations of the above factors imply that size-at-age distributions for a given population can vary among micro-cohorts and years and, consequently, alter the overall population fecundity, which is largely determined by adult size in cephalopods (Mangold 1987). This is especially significant for species that have no overlapping generations and are commercially exploited, because population size and structure in any given year are direct functions of the success of breeding and recruitment from the previous year (Caddy 1983). This can lead to large inter-annual changes in abundance and render the population less likely to recover from overfishing, given the lack of multiple generations to compensate for low recruitment in any specific year.

Evaluating the relative influence of the many factors affecting size-at-age would require a precise knowledge of the various conditions experienced by individuals during their life history, such as quantity and quality of food consumed or the exact environmental temperatures experienced at each life stage. Obtaining this specific information for individual animals in the wild is difficult, and, although there has been progress with some species through tagging (Jackson et al. 2005), the low levels of tag retention, short life spans and high natural mortality reducing recapture rates remain problematic (Boyle \& Rodhouse 2005). An increasing number of studies attempt to link the biology of cephalopods to their physical environment in nature (Lefkaditou et al. 2008, Pierce et al. 2008, Sanchez et al. 2008). Some studies have focused on growth and size-at-age in natural squid populations in relation to sea surface temperature (SST) (Hatfield 2000, Ichii et al. 2004, Pecl et al. 2004b), but, due to the lack of information, no other factors affecting size-atage were taken into consideration. Controlled culture experiments provide some indication of the relative impact of different growth determinants (Forsythe \& Hanlon 1988, Segawa \& Nomoto 2002, Leporati et al. 2007) and remain invaluable to investigations of environmental influences on cephalopod life history. However, captivity can introduce biases and alter the actual processes of growth in cephalopods (Pecl \& Moltschaniwskyj 1999). Moreover, changes in temperatures lead to large changes in growth rates and size-at-age (Forsythe et al. 2001, Hatfield et al. 2001), yet most experiments have used static temperature regimes that do not reflect the seasonal temperature variations encountered in nature. 
The purpose of the present study was to use a modelling approach to investigate the relative influence of the principal abiotic (environmental temperature) and biotic factors (food consumption, hatching size, inherent growth capacity) affecting size-at-age in immature octopus. This method represents a complementary approach to both field and laboratory studies as it allows an investigation into the impact of factors such as food consumption in natural populations, which would otherwise not be possible. We generated an individual-based bioenergetics model, which determined the growth trajectories of individuals hatched in different seasons based on food availability, metabolism, environmental temperature and individual variability (i.e. hatchling size and inherent growth capacity). The model was parameterised with a combination of laboratory and field data and was validated against size-at-age data of wild individuals. We determined the level of individual variability in growth and food intake necessary to encompass the variation in size-at-age observed in our sample. We assessed the relative influence of individual variability and food availability on size-at-age, as well as the impact of food availability on the percentage of individuals displaying 2-phase growth and the age and size at the onset of sexual maturation. Our study species was the commercially exploited pale octopus Octopus pallidus, a temperate, medium-sized octopus ( 0.8 to $1.2 \mathrm{~kg}$ ) with a 12 to $18 \mathrm{mo}$ life span (Leporati et al. 2008b). Populations of this species show very little overlap in generations despite deposition of eggs all year round (Leporati et al. 2008b). Given that reproductive growth in octopus differs between sexes in both energy allocation and timing (Semmens et al. 2004), we chose, on the grounds of model parsimony, to limit our analysis to size-at-age in immature animals. In addition, as no immature males were caught during the 2 yr of sampling (Leporati et al. 2008a) upon which the present study was based, we focused the model on females only.

\section{MATERIALS AND METHODS}

Dataset. A total of 409 female Octopus pallidus were collected between 2004 and 2006 using a bottom set long line of octopus pots set at $26 \mathrm{~m}$ depth in Bass Strait waters, Tasmania, Australia $\left(40^{\circ} 43.342^{\prime} \mathrm{S}, 145^{\circ} 20.060^{\prime} \mathrm{E}\right.$ ) (see Leporati et al. 2008a for details of the sampling regime). Individuals were weighed, aged via daily increments in the stylet (Leporati et al. 2008b), sexed and their reproductive status assessed
(Leporati et al. 2008a). For the purpose of the present study, we selected all immature females hatched in January ( $\mathrm{n}=12)$, May ( $\mathrm{n}=12)$ and July $(\mathrm{n}=18) 2005$ to represent cohorts hatched in (austral) summer, autumn and winter, respectively. The dataset contained too few immature females hatched in spring 2005 for that seasonal cohort to be represented in our simulations. Gear selectivity and the large numbers of microcohorts within a year contributed to the low number of suitable data points. Given the high individual variability present in octopus, the sample sizes were nevertheless deemed sufficient to represent the range of size-at-age attainable in the wild.

Model development. The basis of the model was the temperature-dependent energy balance model (TEBM) described by André et al. (2009), which determines the shape and duration of the exponential growth phase in female octopus. The modified version presented here, the dynamic temperature-dependent energy balance model (DTEBM), allows the growth pattern of wild octopus hatched in different seasons to be simulated by adding the second growth phase, individual variability and dynamic temperatures to the original TEBM. Fig. 1 synthesizes the modelling approach used in the present study.

TEBM concept: The TEBM is based on the concept that cephalopod growth is bi-phasic and that energy conservation enforces the shift in growth between the 2 phases. The supply of energy $E$ available to an individual depends on the balance between the energy

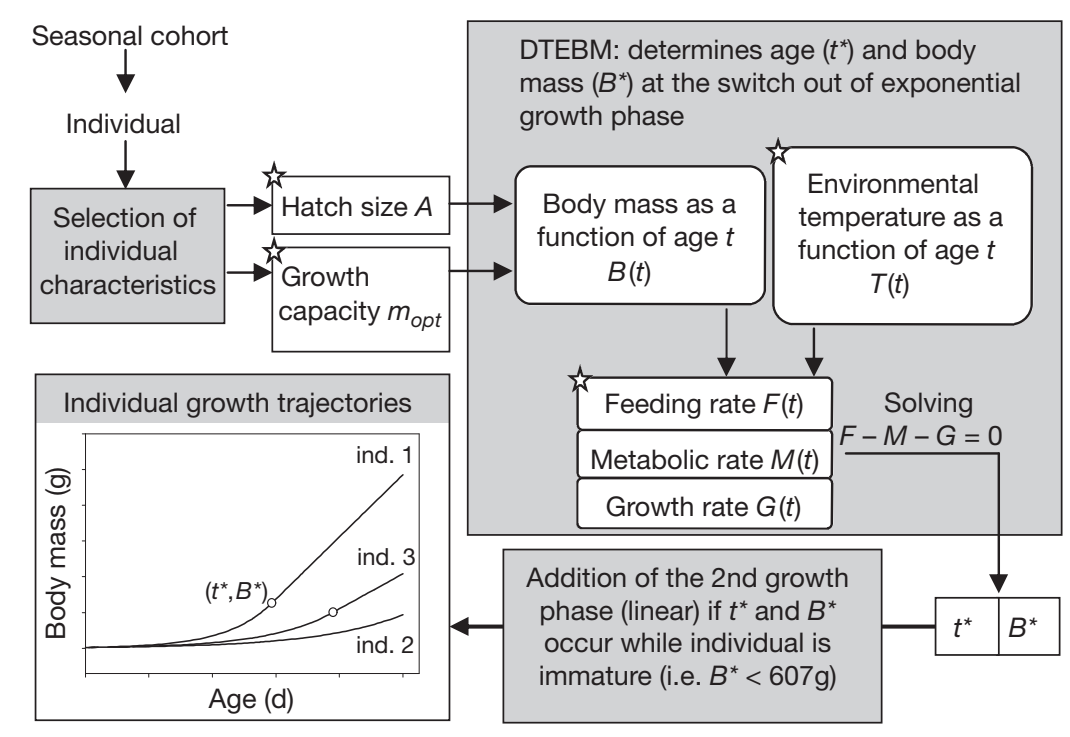

Fig. 1. Schematic representation of the modelling approach used to estimate individual growth trajectories. The purpose of the model was to investigate the relative influence of environmental temperature, food consumption, hatching size and inherent growth capacity (boxes marked with a star) on size-at-age in immature octopus Octopus pallidus 
gained through food intake and the energy expended in metabolism and growth so that:

$$
E=F-M-G
$$

where $F$ is the energy intake rate from food, $M$ and $G$ are the respective rates at which energy is expended in metabolism and somatic growth, respectively, and $E$ must remain positive for the individual to survive. These rates are expressed in kilojoules per day in the present paper. Reproductive growth is not included here because we are concerned with immature individuals only. Grist \& Jackson (2004) noted that all 3 terms on the right-hand side of Eq. (1) are dependent on body mass $B$, implying the possible existence of a threshold size $B^{*}$ when $E=0$. The feeding $(F)$ and metabolic $(M)$ rates traditionally follow an allometric scaling law of the form $Y=q B^{p}$ where $p>0$ is a scaling exponent and $q>0$ is a constant (West et al. 1997, Boyle \& Rodhouse 2005, O'Dor et al. 2005). As growth is initially exponential, the initial growth rate $G$ is directly proportional to body mass. All 3 rates are dependent on body mass $B$ and environmental temperature T, and Eq. (1) can be re-expressed as:

$$
\begin{aligned}
E(B, T) & =F(B, T)-M(B, T)-G(B, T) \\
& =q_{1}(T) B^{p_{1}}-q_{2}(T) B^{p_{2}}-q_{3}(T) B
\end{aligned}
$$

where $p_{1}$ is the feeding exponent, $p_{2}$ the metabolic exponent and the functions $q_{i}(T)$ determine the temperature-dependency for the specific rate. Temperature dependency of feeding rate $q_{1}(T)$ and growth rate $q_{3}(T)$ were modelled with an inverted parabola to represent the general non-linear decrease in feeding and growth rates observed towards extreme temperatures (e.g. Ricker 1979, Mangold 1983, Bartsch 2002, André et al. 2009). This model has an optimum, corresponding to the maximum growth rate, and a symmetrical drop off on both sides (or asymmetrical if the optimum is not the midpoint of the species' temperature range). Assuming food is not a limiting factor, the temperature mediation of the growth rate is given by a symmetric inverted parabola:

$$
q_{3}(T)=k_{3} m(T)=k_{3}\left(m_{\mathrm{opt}}-h\left(T_{\mathrm{opt}}-T\right)^{2}\right)
$$

where $k_{3}$ is the energy equivalent of octopus tissue, $m(T)$ is the growth rate coefficient, $m_{\text {opt }}$ is the maximum value of $m(T)$ at the optimum temperature for growth $T_{\text {opt }}, h$ is a constant and $T$ is the ambient temperature. Similarly, the temperature mediation of the feeding rate is given by an asymmetric inverted parabola:

$$
q_{1}(T)= \begin{cases}f_{\mathrm{opt}}-h_{f 1}\left(T_{f \mathrm{opt}}-T\right)^{2} & T<T_{f \mathrm{opt}} \\ f_{\mathrm{opt}}-h_{f 2}\left(T_{f \mathrm{opt}}-T\right)^{2} & T>T_{f \mathrm{opt}}\end{cases}
$$

where $T_{\text {fopt }}$ is the optimum temperature for maximum feeding rate $f_{\text {opt }}$, and $h_{f 1}$ and $h_{f 2}$ are constants. These equations represent the general case; it is worth noting that both feeding and growth rates may be improved at lower temperatures, for example, in areas subjected to upwelling (Jackson \& Domeier 2003).

The temperature dependency of metabolic rate $q_{2}(T)$ is given by a modification of the Katsanevakis et al. (2005) equation:

$$
q_{2}(T)=k_{1} \mathrm{e}^{\left(a_{2}+\frac{b_{2}}{T+k_{2}}\right)}
$$

where $k_{1}$ is the conversion factor from milligrams per hour to kilojoules per day, $k_{2}$ is the conversion factor from Kelvin to degrees Celsius, and $a_{2}$ and $b_{2}$ are constants.

When $E(B, T)=0$ (Eq. 2), the individual reaches a threshold body mass $B^{*}$ at a corresponding age $t^{*}$, after which it will no longer be able to cover its total energy expenditure rate. It is postulated that a shift from exponential growth to a slower growth phase is then enforced (Grist \& Jackson 2004, 2007).

DTEBM and the estimation of the exponential growth phase: Whereas the TEBM describes growth at a fixed temperature, the DTEBM incorporates temperature dependence, which enables growth to be described under a seasonally fluctuating temperature environment (see Table 1 for description and values of DTEBM terms). We used a standard sinusoidal temperature function:

$$
T=T_{0}+T_{1} \cos k\left(t+t_{\text {hatch }}+c\right)
$$

to represent seasonal environmental temperature $T$ as a function of time of the year $\left(t+t_{\text {hatch }}\right)$, where $t$ is the age of the individual (in days), $t_{\text {hatch }}$ is the hatching day in a $365 \mathrm{~d}$ year, $T_{0}$ is the mean annual temperature (baseline), $T_{1}$ is the annual fluctuation of temperature around $T_{0}$ (amplitude), $k$ is the frequency and $c$ is the time lag necessary to align the maximum of the curve to the occurrence of the maximum temperature in a year (shift). Temperature parameters were determined from SST data for the years 2005/2006; the data were downloaded from the National Oceanic and Atmospheric Administration (NOAA) web site (www. noaa.gov).

Body mass is traditionally expressed as:

$$
B(t)=A \mathrm{e}^{m t}
$$

where $t$ is the post-hatch age, $A$ is the hatchling size and $m$ is the fixed growth rate $\left(\mathrm{d}^{-1}\right)$. However, the growth rate coefficient $m$ in this model is temperature dependent, so that body mass is now given by (see Appendix 1 for details of the calculation):

$$
\begin{aligned}
& B(t)=A \mathrm{e}^{I(t)} \\
& \text { where } \quad I(t)=\int m(t) \mathrm{d} t \\
& \text { and } m(t)=m_{\mathrm{opt}}-h\left(T_{\mathrm{opt}}-T\right)^{2} \\
& =m_{\mathrm{opt}}-h\left(T_{\mathrm{opt}}-\left(T_{0}+T_{1} \cos k\left(t+t_{\text {hatch }}+c\right)\right)\right)^{2}
\end{aligned}
$$


Table 1. Equations and parameter values for the dynamic temperaturedependent energy balance model (DTEBM). A: hatchling size; $t$ : age (in days); $t_{\text {hatch }}$ : hatching day in a 365 d year

\begin{tabular}{|c|c|}
\hline Equations and parameters & Values \\
\hline \multicolumn{2}{|l|}{ Growth rate $\boldsymbol{G}: q_{3}(T) B$ with $q_{3}(T)$ from Eq. (3) } \\
\hline Optimum temperature for growth $\left(T_{\text {opt }}\right)\left({ }^{\circ} \mathrm{C}\right)$ & 16.5 \\
\hline Growth rate coefficient at $T_{\text {opt }}\left(m_{\text {opt }}\right)\left(\mathrm{d}^{-1}\right)$ & 0.0217 to 0.0967 \\
\hline Parabolic constant $(h)$ & $5.14 \times 10^{-4}$ to $2.3 \times 10^{-3}$ \\
\hline Energy equivalent of octopus tissue $\left(k_{3}\right)\left(\mathrm{kJ} \mathrm{g}^{-1}\right)$ & 4.05848 \\
\hline \multicolumn{2}{|l|}{ Feeding rate $\boldsymbol{F}: q_{1}(T) B^{p 1}$ with $q_{1}(T)$ from Eq. (4) } \\
\hline Optimum temperature for feeding $\left(T_{\text {fopt }}\right)\left({ }^{\circ} \mathrm{C}\right)$ & 18.4 \\
\hline Feeding rate at $T_{f \text { opt }}\left(f_{\text {opt }}\right)\left(\mathrm{kJ} \mathrm{d}^{-1}\right)$ & 2.044 \\
\hline \multirow{2}{*}{$\begin{array}{ll}\text { Parabolic constant } & \text { if } T \leq T_{f o p t}\left(h_{f 1}\right) \\
& \text { if } T>T_{f o p t}\left(h_{f 2}\right)\end{array}$} & 0.029 \\
\hline & 0.0966 \\
\hline Feeding rate exponent $\left(p_{1}\right)$ & 0.75 \\
\hline \multicolumn{2}{|l|}{ Metabolic rate $\boldsymbol{M}: q_{2}(T) B^{p 2}$ with $q_{2}(T)$ from Eq. (5) } \\
\hline Metabolic rate exponent $\left(p_{2}\right)$ & 0.88 \\
\hline Conversion factor $\left(\mathrm{O}_{2} \mathrm{mg} \mathrm{h}^{-1}\right)$ to $\left(\mathrm{kJ} \mathrm{d}^{-1}\right)\left(k_{1}\right)$ & 0.33758 \\
\hline Conversion factor $\left(\mathrm{K}\right.$ to $\left.{ }^{\circ} \mathrm{C}\right)\left(k_{2}\right)$ & 273.15 \\
\hline Constant $\left(a_{2}\right)$ & 21.80 \\
\hline Constant $\left(b_{2}\right)$ & -6952.8 \\
\hline \multicolumn{2}{|l|}{ Temperature $T$ : (Eq. 6) } \\
\hline Baseline $\left(T_{0}\right)$ & 15.06 \\
\hline Amplitude $\left(T_{1}\right)$ & 2.83 \\
\hline Frequency $(k)$ & $2 \times \mathrm{pi} / 365$ \\
\hline Shift $(c)$ & -73 \\
\hline \multicolumn{2}{|l|}{ Body mass B: (Eq. 8) } \\
\hline$A \mathrm{e}^{\int \mathrm{J}(t) \mathrm{d} t}$ & \\
\hline
\end{tabular}

Food consumption in wild octopus. We evaluated average food consumption in captive Octopus pallidus on a crab diet (André et al. 2009) and estimated the parameters for the feeding rate $F(t)=q_{1}(t) B^{p_{1}}$. The optimum temperature for maximum feeding $T_{\text {fopt }}$ was estimated at $18.4^{\circ} \mathrm{C}$ for this species. The corresponding $f_{\text {opt }}$ was estimated at $0.584\left(\mathrm{~kJ} \mathrm{~d}^{-1}\right)$ and the feeding rate exponent $p_{1}$ at 1.17 . Specimens reared in the laboratory are held in an impoverished environment with limited food choice, tactile and visual stimuli, as well as restricted space. These factors may lead to suboptimal feeding (Houlihan et al. 1998), and it is reasonable to assume that the $f_{\text {opt }}$ value would be higher in the wild. Moreover, a value of $p_{1}>1$ signifies that individuals always have enough energy intake to cover growth and metabolic costs, which is unlikely to be the case for animals in nature. A range of $f_{\text {opt }}$ and $p_{1}$ values were therefore tested to identify plausible estimates for wild animals. For $p_{1}$, we explored a range of values from 0.40 to 1 in 0.05 increments, based on the lowest $p_{1}$ value of 0.39 described for an octopus species (Octopus ocellatus; André et al. 2009). For $f_{\text {opt, }}$ we tested values up to 4 times the $f_{\text {opt }}$ value found in the laboratory, corresponding to a range of values from 0.584 to 2.336 in increments of 0.292 . Values $>2.336\left(\mathrm{~kJ} \mathrm{~d}^{-1}\right)$, equivalent to a food consumption in excess

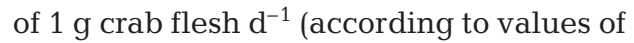
O'Dor \& Wells 1987) for a $0.3 \mathrm{~g}$ hatchling, were deemed too high for juveniles of this species.

By incorporation of $B(t)$ and $T(t)$ in Eq. (2), we obtain

$$
E(t)=F(t)-M(t)-G(t)
$$

where

$$
\begin{aligned}
& F(t)=q_{1}(T(t)) B(t)^{p_{1}} \\
& M(t)=q_{2}(T(t)) B(t)^{p_{2}} \\
& G(t)=q_{3}(T(t)) B(t)
\end{aligned}
$$

The post-hatch age and body mass at which the exponential growth phase terminates in an individual were defined as $t^{*}$ and $B^{*}$, respectively. Using Eq. (10), an iterative search was conducted for the threshold age $t^{*}$, which achieves $E(t)=0$.

The corresponding body mass $B^{*}$ was calculated according to

where

$$
B^{*}=B\left(t^{*}\right)=A \mathrm{e}^{I\left(t^{*}\right)}
$$

$$
I\left(t^{*}\right)=\int_{0}^{t^{*}} m(t) \mathrm{d} t
$$

Individual variability. We introduced individual variability at 2 levels: (1) variation in hatchling size (parameter $A$ in Eq. 7) and (2) variation in inherent growth capacities (parameter $m_{\text {opt }}$ in Eq. 9). We assumed that variation in inherent growth capacity and variation in hatchling size acted independently.

Hatchling size varies both within a cohort (intracohort variation) and between seasons (inter-cohort variation) (Pecl et al. 2004a). The model was parameterised with 3 seasonal distributions, namely summer, autumn and winter distributions for hatchling size, from which individuals were randomly selected. To do this, we first estimated the population variability in hatchling size from data obtained for 58 individuals hatched in winter (June) 2005 from a single brood originating from Bass Strait waters and maintained at ambient temperature in the laboratory (Leporati et al. 2007). The June hatchling distribution approximately 

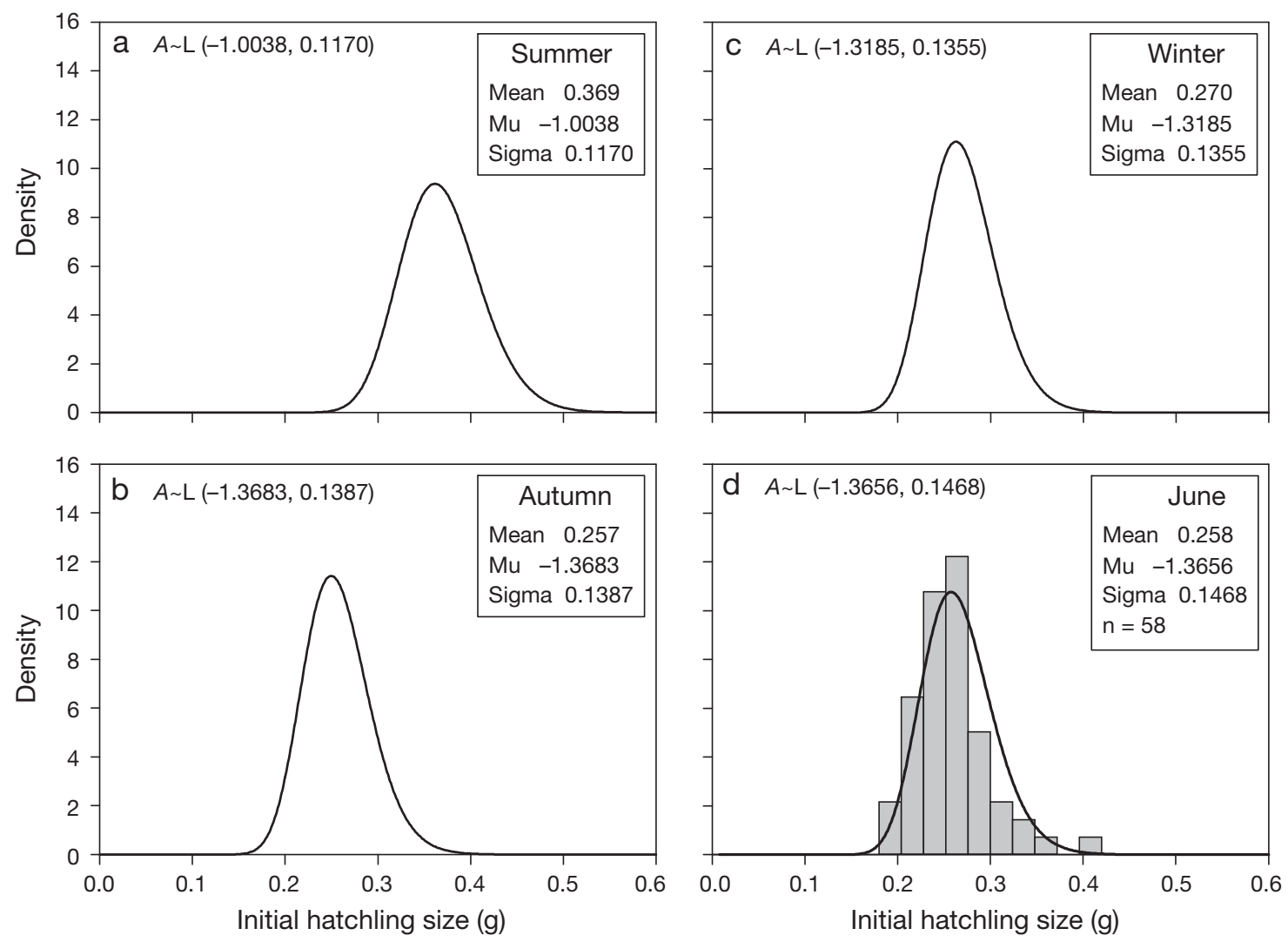

Fig. 2. Octopus pallidus. Hatchling size $(A)$ selected from a log-normal distribution (L) defined by mu and sigma for: (a) summer, (b) autumn and (c) winter. Distributions were estimated statistically (see 'Materials and methods' section). (d) Estimated and observed June hatchling size distribution

followed a log-normal distribution (Fig. 2d) and was used as a template for the summer, autumn and winter seasonal hatchling size distributions (Fig. 2a to c), based on the following assumptions:

- The mean of the hatching size distribution is a function of incubation duration.

- While incubation duration in days varies with environmental temperature (Boletzky 1994), incubation duration in degree-days remains constant independent of the season. Incubation in degree-days (incubdd) was calculated according to:

$$
\text { incubdd } \left.=\sum_{1}^{\text {incubdays }} \text { (dailytemp }-T_{\text {null }}\right)
$$

where incubdays is the observed number of days of incubation for the June cohort, dailytemp is the daily temperature and $T_{\text {null }}$ is the threshold development temperature for Octopus pallidus eggs. Based on a threshold development temperature of $8^{\circ} \mathrm{C}$, an observed incubdays of $150 \mathrm{~d}$ and known environmental temperature records from both Bass Strait (NOAA) and the laboratory, we estimated the incubation period to be 1067.5 degree-days.

- The relationship between the mean of the initial hatchling size distributions and incubation time (in days) is positively linear (Fig. 3a). Based on the incubation duration in degree-days, and assuming hatching on the first day of the month, we calculated the incubation duration (in days) for each monthly cohort using NOAA temperatures from the Bass Strait region (Table 2). We assumed the mean of the June hatchling size distribution to be that of our experimental brood (i.e. $0.258 \mathrm{~g}$ ) and the proportional change in mean hatchling size to be $0.5 \% \mathrm{~d}^{-1}$ of additional incubation. This was based on an observed change in hatchling size of $25 \%$ for a 48 d difference in incubation duration between the summer and autumn cohorts in Sepiotheuthis australis (Pecl et al. 2004a), a species with a similar thermal range and hatchling size.

- The relationship between mean and variance of the initial hatchling size distributions is positively linear (Fig. 3b).

Inherent individual variability (both genotypic and phenotypic) was incorporated into the model via the parameter $m_{\text {opt }}$ by assigning a specific 'growth potential' to each individual during the first (exponential) phase of growth before the start of the simulation. Values for the parameter $m_{\text {opt }}$ were randomly 
Table 2. Octopus pallidus. Predicted incubation time in Bass Strait waters (based on an incubation duration of 1067.5 degree-days) and mean of the hatchling size distribution. Asterisk represents observed data for pale octopus

\begin{tabular}{|lcc|}
\hline Hatch month & Incubation (d) & Mean hatchling size (g) \\
\hline Jan & 197 & 0.369 \\
Feb & 181 & 0.347 \\
Mar & 148 & 0.303 \\
Apr & 122 & 0.268 \\
May & 114 & 0.257 \\
Jun & 115 & $0.258^{*}$ \\
Jul & 124 & 0.270 \\
Aug & 137 & 0.288 \\
Sep & 154 & 0.311 \\
Oct & 171 & 0.334 \\
Nov & 186 & 0.354 \\
Dec & 196 & 0.367 \\
\hline
\end{tabular}

selected from a uniform distribution $m_{\mathrm{opt}} \sim U\left(\min _{-}\right.$ $\left.m_{\text {opt }}, \max _{-} m_{\text {opt }}\right)$, resulting in a different growth rate coefficient $m(t)$ for each individual (Fig. 4). As an initial estimate, we set the lower limit of the uniform distribution min_m $m_{\text {opt }}$ to $0.0167\left(\mathrm{~d}^{-1}\right)$, corresponding to the $m_{\mathrm{opt}}$ value observed for Octopus pallidus in the laboratory at $16.5^{\circ} \mathrm{C}$ (André et al. 2009), and the upper limit max $m_{\text {opt }}$ to $0.098\left(\mathrm{~d}^{-1}\right)$, corresponding to highest published growth rate for an octopus species in its exponential growth phase (Octopus burryi; Forsythe \& Hanlon 1985), so that $m_{\mathrm{opt}} \approx U(0.0167$, $0.098)$. We varied the min $\_m_{\text {opt }}$ and max $\_m_{\text {opt }}$ in 0.005 increments, so that min $\_m_{\mathrm{opt}}=\{0.0167,0.027,0.0267$, $0.0317,0.0367\}$ and max $\_m_{\text {opt }}=\{0.073,0.078,0.083$, $0.088,0.093\}$, and used the resulting uniform distributions to find a value pair (min_m $m_{\text {opt }}$, max $\left.\_m_{\text {opt }}\right)$ that reflected the data most accurately in the simulated projection.

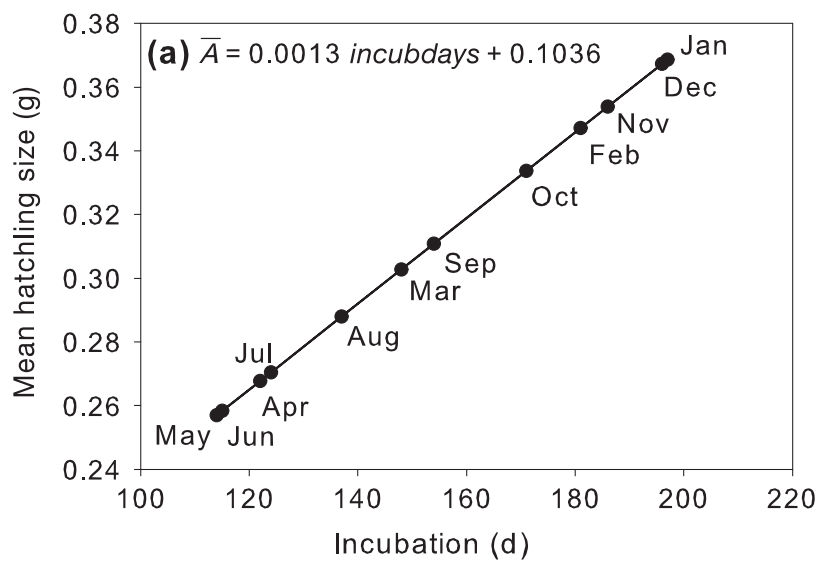

Second slower growth phase. In Octopus pallidus, the sub-adult/adult growth phase does not appear to be influenced by temperature and seems to be exponential in form, although slower than the first exponential phase (Hoyle 2002, Semmens et al. 2004). There is, however, no information on the gradient of change in exponential growth between the phases of growth. Therefore, for model parsimony, we represented the second growth phase as linear and tangential to the transition point $\left(t^{*}, B^{*}\right)$, as employed in Grist \& Jackson (2007) (Fig. 5).

Sexual maturation. The onset of sexual maturation appears to be dictated by body mass rather than age in the pale octopus, with the mass at $50 \%$ maturity estimated for wild females at $472 \mathrm{~g}$ (Leporati et al. 2008a). However, the age and body mass at sexual maturity also depend on the food available to an individual (Mangold 1987), although the form of the relationship is not well defined. Given the lack of information on food consumption and its relation to sexual maturity in wild animals, we asserted that the body mass of the largest immature female found in the sampling year from which our data were extracted (i.e. 2005) would be the maximum body mass achievable by a juvenile in that specific year (i.e. $607 \mathrm{~g}$ ). We therefore used $607 \mathrm{~g}$ as the body mass at which sexual maturity is achieved in our model (Fig. 5).

Other model assumptions. The following model assumptions were also made:

(1) Potential differences in activity levels are not taken into consideration; therefore, there is no individual variability in oxygen consumption rate other than that produced by differences in environmental temperature and body mass (i.e. individuals the same size and experiencing the same temperature regime will have identical oxygen consumption rates).

(2) All individuals within a micro-cohort have the same diet (crab) and have access to the same level of

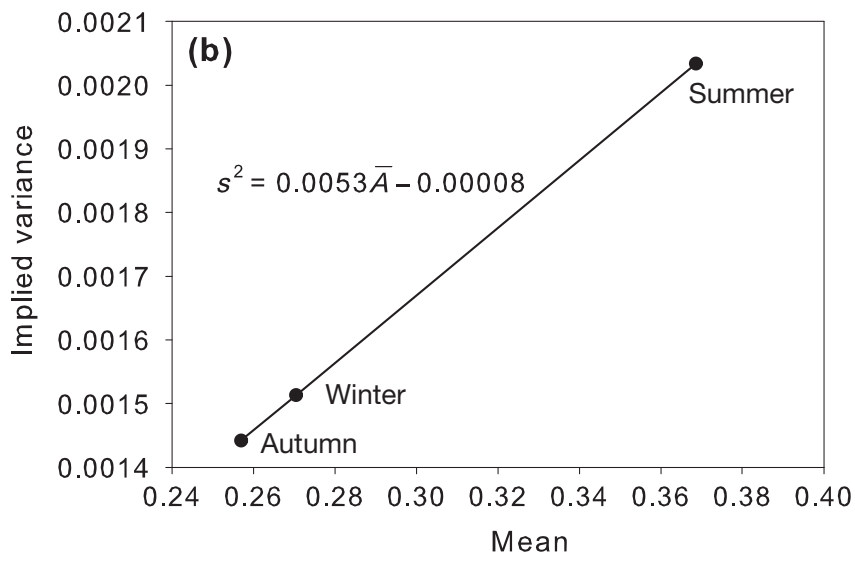

Fig. 3. Octopus pallidus. Estimation of seasonal hatchling size distribution parameters: (a) relationship between incubation time (incubdays) and mean of the hatchling size distribution $(\bar{A})$ and (b) relationship between mean hatchling size $(\bar{A})$ and variance $\left(s^{2}\right)$ used to estimate the summer, autumn and winter hatchling size distributions 


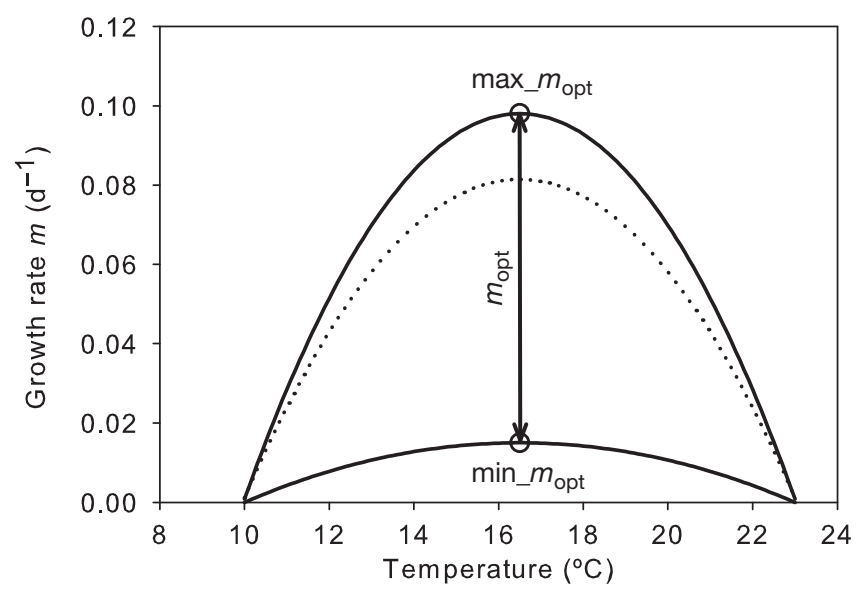

Fig. 4. Octopus pallidus. Plot of the exponential growth rate coefficient $m$ as a function of temperature $T$. Inverted parabolic curves of the form $y=m_{\mathrm{opt}}-h\left(T_{\mathrm{opt}}-T\right)^{2}$ were used to describe $m(T)$. Inherent growth capacity was represented in the model by randomly selecting an $m_{\text {opt }}$ value from a uniform distribution $U\left(\min \_m_{\text {opt }}\right.$, max $\left.\_m_{\text {opt }}\right)$ and assigning the resulting $m(T)$ curve (e.g. dotted line) to each hatchling at the start of the simulation

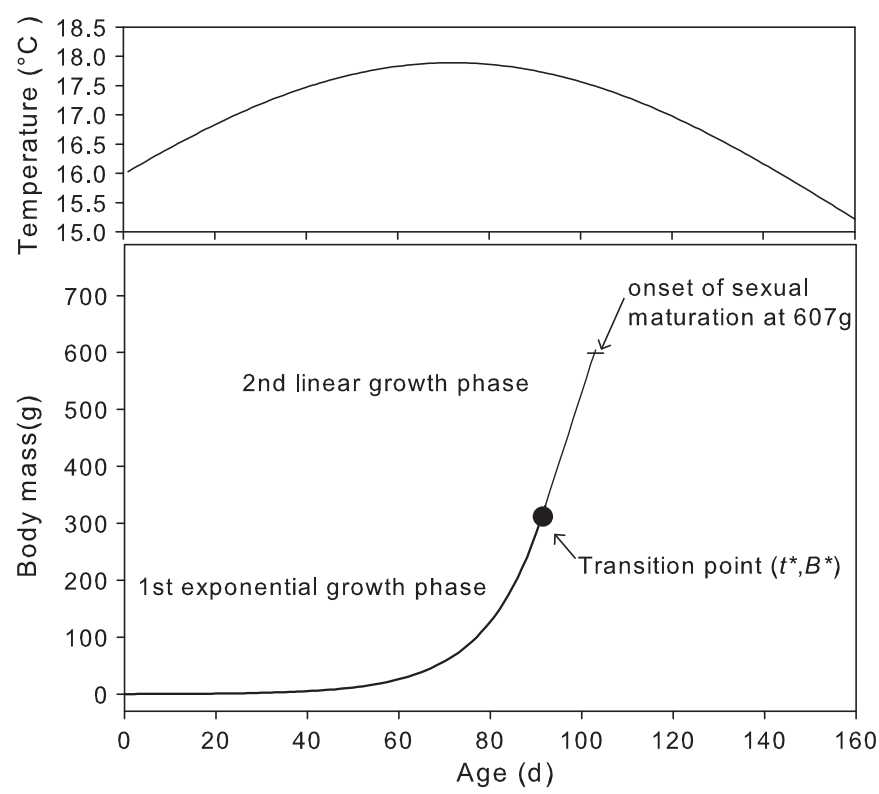

Fig. 5. Octopus pallidus. Plot of the projected individual growth trajectory (here a 2-phase growth pattern) of a summer-hatched individual parameterised with an initial hatchling size $A=0.194 \mathrm{~g}$, optimum growth rate $m_{\mathrm{opt}}=0.083 \mathrm{~d}^{-1}$ and optimum feeding rate $f_{\text {opt }}=1.49 \mathrm{~kJ} \mathrm{~d}^{-1}$

food. Hence, there is no individual variability in food consumption other than that produced by differences in environmental temperature and body mass.

(3) As octopus are opportunistic predators, there is no inter-seasonal variation in food consumption (i.e. the feeding parameters remain the same independent of season).
Simulation. We simulated 3 seasonal micro-cohorts, each containing 200 individuals, which were started on 1 January (summer cohort), 1 May (autumn cohort) and 1 July (winter cohort) 2005. Individual juvenile growth trajectories within each micro-cohort were projected up to a body mass of $607 \mathrm{~g}$, corresponding to the assumed size at maturity. Simulations were aimed at investigating the influence of environmental temperature, food consumption, hatchling size and inherent growth capacity on size-at-age. Juvenile mortality was not taken into consideration in the projections.

The model was first tuned by adjusting the feeding constant $f_{\text {opt }}$, the feeding exponent $p_{1}$ and the range of possible optimum growth rates (min_m $m_{\text {opt }}, \max \_m_{\text {opt }}$ ), until the size-at-age data observed in wild ocotopus were contained within the 5th to 95th percentile range of size-at-age produced by the model for each season.

We then investigated the influence of seasonal temperature on size-at-age for each micro-cohort from projections of the body mass distributions of immature individuals. As the age of the youngest mature individual in each of our seasonal samples varied between 3.75 and $5 \mathrm{mo}$, we projected size-at-age up to $4 \mathrm{mo}$ of age (namely at 60, 90 and $120 \mathrm{~d}$ ) in order to include as many immature simulated individuals as possible in our analyses. The relative influence of individual variability in hatchling size and in inherent growth capacity on the simulations were determined independently, by randomising the respective parameters $A$ or $m_{\text {opt }}$ whilst holding the other parameter constant either at the mean $m_{\text {opt }}$ or the mean value of hatchling size $A$ (i.e. randomised $A$ with fixed $m_{\text {opt }}$ or randomised $m_{\text {opt }}$ with fixed $A$ ). We investigated the influence of food availability by altering the $f_{\text {opt }}$ value from 0.584 to $2.336\left(\mathrm{~kJ} \mathrm{~d}^{-1}\right)$ in increments of 0.292 (corresponding to $1.5-4$ times the $f_{\text {opt }}$ value estimated for laboratory animals), and then assessing the impact on size-at-age, the proportion of individuals displaying 2-phase growth and age at $50 \%$ sexual maturity (estimated here as the age at which $50 \%$ of the individuals have reached $607 \mathrm{~g}$ ).

\section{RESULTS}

\section{Estimation of growth and feeding parameters for wild-caught octopus}

An $m_{\text {opt }}$ range of 0.0217 to $0.0967\left(\mathrm{~d}^{-1}\right)$ was necessary to encompass all the variability observed in our sample of wild-caught octopus, and we subsequently used the distribution $m_{\mathrm{opt}}=U(0.0217,0.0967)$ for the rest of the analyses. While other feeding parameter combinations provided acceptable model fits under the selected $m_{\mathrm{opt}}$ range, the combination of $0.75\left(p_{1}\right)$ and $2.044\left(f_{\text {opt }}\right)$ pro- 
vided the most plausible representation of the predicted size-at-age, which tightly surrounded the available data (Fig. 6). This combination was used to explore predicted size-at-age at 60,90 and $120 \mathrm{~d}$ and the age at sexual maturity in our sample.

An $f_{\text {opt }}$ value of 0.584 was deemed improbable under natural conditions as it resulted in unrealistically slow growth of individuals. This $f_{\text {opt }}$ value was removed from subsequent analyses, so that only the range from 0.876 to 2.336 was used to estimate the influence of food intake on size-at-age and age at sexual maturity.
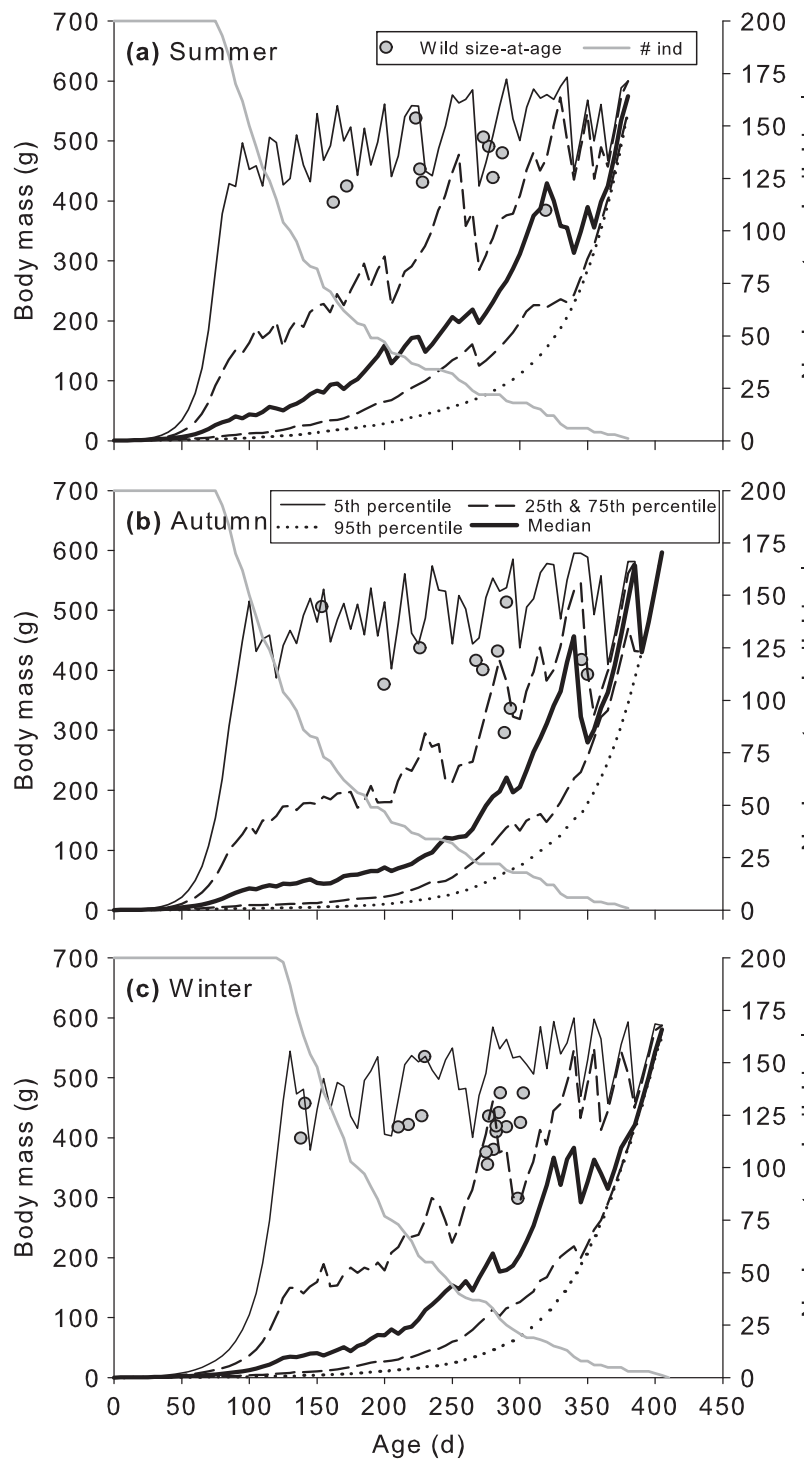

Fig. 6. Octopus pallidus. Simulated size-at-age (with both optimum growth rate $m_{\text {opt }}$ and hatchling size $A$ randomised) for immature octopus $(n=200)$ hatched in: (a) summer, (b) autumn and (c) winter. Thin solid lines: 5th percentile; dotted lines: 95th percentile; dashed lines: 25th and 75th percentile; thick solid lines: median; solid grey lines: number of immature individuals left in the model; circles: size-at-age data of wild individuals from the Bass Strait fishery

\section{Projected size-at-age at 60, 90 and $120 \mathrm{~d}$}

Size-at-age within a cohort was extremely variable (Fig. 7), with an up to 435 -fold difference between the smallest and largest individuals at $120 \mathrm{~d}$. Variability increased with time in all seasons, but the range of possible sizes attained was smaller for the winter cohort up to $90 \mathrm{~d}$ ( 2.4 to $579 \mathrm{~g}$ for summer cohort, 1.4 to $570 \mathrm{~g}$ for autumn cohort and 0.8 to $119 \mathrm{~g}$ for winter cohort). Individuals hatched in summer consistently grew faster and reached a larger size than those hatched in other sea-
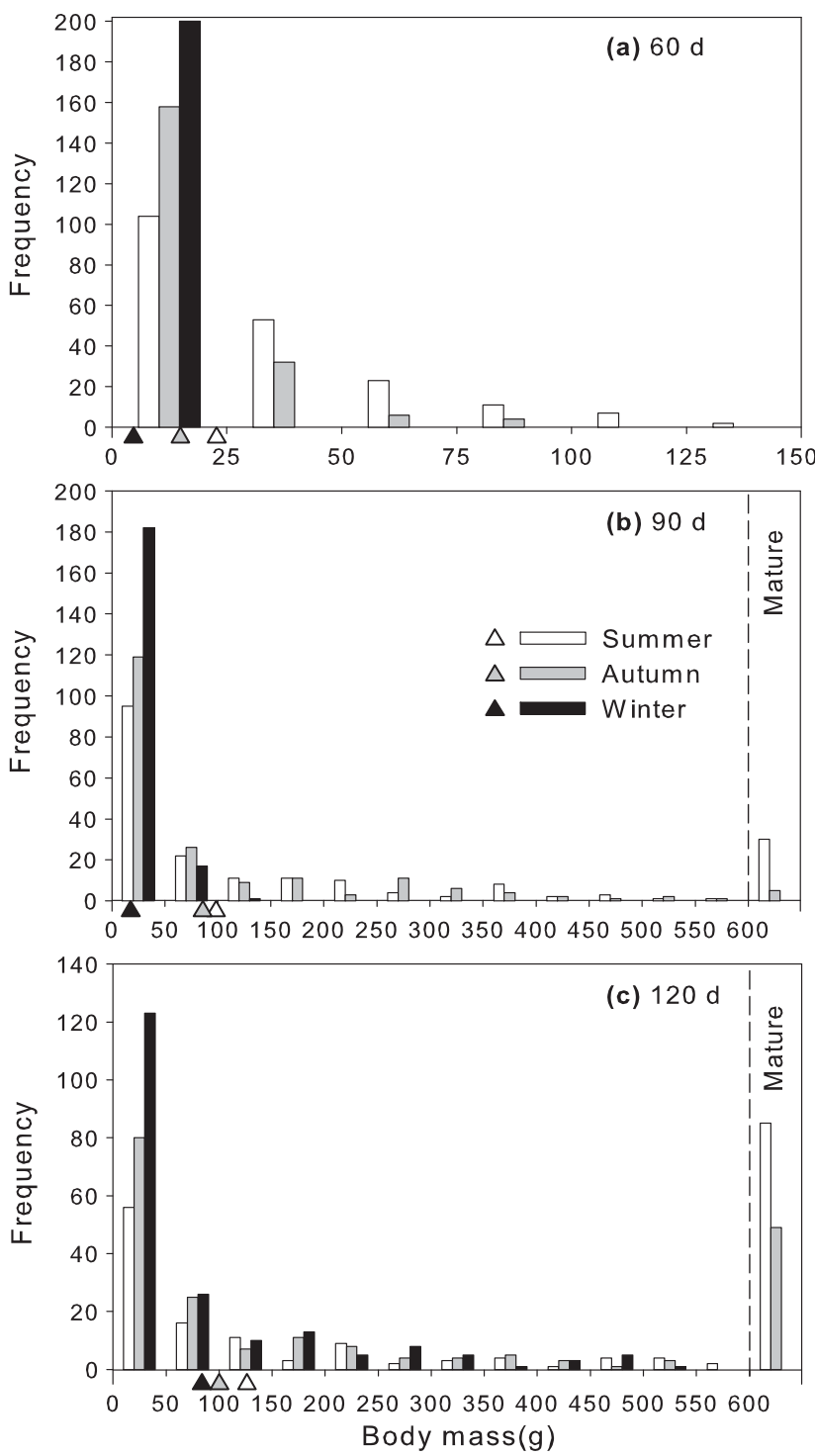

Fig. 7. Octopus pallidus. Simulated body mass distributions (with both optimum growth rate $m_{\text {opt }}$ and hatchling size $A$ randomised) for summer-, autumn- and winter-hatched octopus (n = 200) at: (a) 60, (b) 90 and (c) 120 d. Seasonal mean body mass values are represented by triangles. Note the different scale for the $x$-axis in (a). Also, note that at 90 and $120 \mathrm{~d}$, some individuals in the summer and autumn simulations had already reached maturity $(607 \mathrm{~g})$ 
sons. The autumn cohort was the second fastest growing cohort and presented a similar size-at-age distribution to summer-hatched individuals. At $120 \mathrm{~d}, 42 \%$ of the summer-hatched individuals had reached $607 \mathrm{~g}$, compared to $24.5 \%$ of the autumn-hatched individuals, and were removed from the projection. Winterhatched individuals presented the smallest size-at-age distribution of the 3 seasons, reaching only $2 / 3$ of the size of their summer counterparts at $120 \mathrm{~d}$ (mean body mass: $83.9 \mathrm{~g}(\mathrm{n}=200)$ for the winter cohort and $126.3 \mathrm{~g}$ $(n=116)$ for the summer cohort).

\section{Projected age at sexual maturity}

The onset of sexual maturity, represented by a drop in the cohort's median body mass as the first individuals reached $607 \mathrm{~g}$ and 'moved out' of the model, differed between seasons. Summer-hatched individuals reached sexual maturity earlier than individuals hatched in other seasons, with maturation starting at $80 \mathrm{~d}$ for the first individual and $50 \%$ maturation being reached at $130 \mathrm{~d}$. Although there was little difference in the age at $50 \%$ maturity between autumn- and winter-hatched individuals (175 vs. $180 \mathrm{~d}$, respectively), maturation started earlier in autumn-hatched individuals, with the first individuals starting maturity at $90 \mathrm{~d}$ compared to $125 \mathrm{~d}$ for the winter-hatched cohort.

\section{Relative influence of hatchling size and inherent growth capacity on size-at-age}

Hatchling size produced an up to 2-fold difference in size-at-age, but generated less variation than inherent growth capacities independent of hatch season (Fig. 8). The size-at-age variation observed in our sample of wild-caught octopus was not encompassed by either inherent growth capacity or by hatchling size variation alone for the summer cohort.

\section{Projected influence of food intake on size-at-age}

The 3 cohorts presented slightly different patterns with regards to the influence of food availability on size-atage. For all cohorts, increased food availability resulted in larger individuals, with a range of sizes from 0 to $350 \mathrm{~g}$ in summer and 0 to $100 \mathrm{~g}$ in autumn and winter for an $f_{\text {opt }}$ of 0.876 , compared to $0-600 \mathrm{~g}$ for all seasons for an $f_{\text {opt }}$ of 2.336 (Fig. 9c,f,i). The impact of food availability, however, only became apparent at 3 mo of age for the summer and autumn cohorts and at 6 mo of age for the winter cohort, with earlier size-atage distributions being almost identical and indepen-

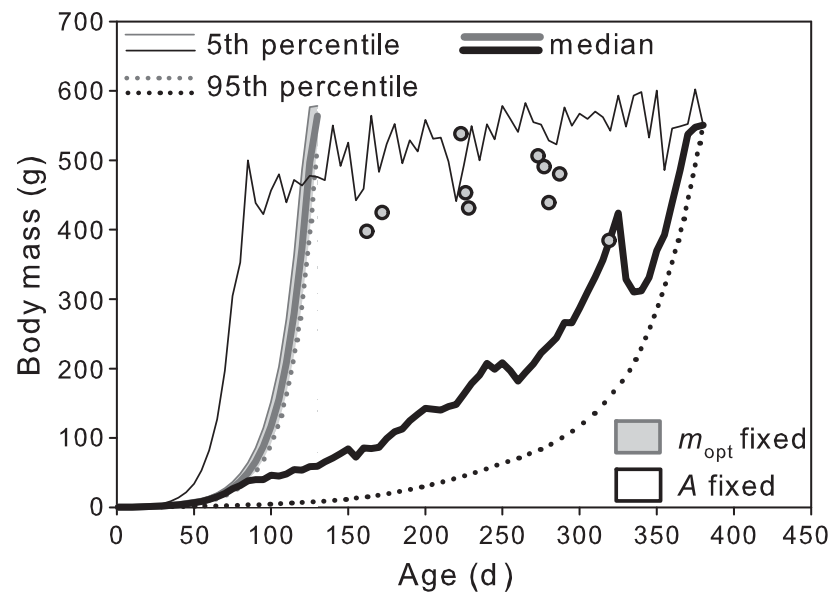

Fig. 8. Octopus pallidus. Simulated size-at-age for immature octopus $(n=200)$ hatched in summer. The relative influence of individual variability was investigated by fixing hatchling size and randomising growth capacity ( $A$ fixed model, black lines) and by fixing inherent growth capacity and randomising hatchling size ( $m_{\mathrm{opt}}$ fixed model, grey lines). Thin solid lines: 5 th percentile; dotted lines: 95 th percentile; thick solid lines: median; circles: size-at-age data of wild individuals from the Bass Strait fishery. The simulated size-at-age for the autumn and winter cohorts encompassed all the size-at-age data of wild individuals and were not presented here for conciseness

dent of $f_{\text {opt }}$. Summer and autumn cohorts also became bi-modal at $120 \mathrm{~d}$ under certain food intake levels, namely $f_{\text {opt }}=0.876$ and 1.168 for summer and $f_{\text {opt }}=$ 1.168 and 1.46 for autumn (Fig. 9c,f).

Higher food availability also resulted in a lower proportion of individuals displaying 2-phase growth within each cohort (Table 3). An optimum feeding rate $f_{\text {opt }}$ of $2.336 \mathrm{~kJ} \mathrm{~d}^{-1}$ enabled between 87 and $100 \%$ of all individuals to grow exponentially for the entire duration of their juvenile phase depending on the hatching season, whereas $f_{\text {opt }}$ values of $0.876 \mathrm{~kJ} \mathrm{~d}^{-1}$ forced between 74.5 and $89 \%$ of all individuals to display 2phase growth.

\section{Projected influence of food intake on age at sexual maturity}

Increased food availability (up to $f_{\text {opt }}=1.46 \mathrm{~kJ} \mathrm{~d}^{-1}$ for the summer and autumn cohorts and $f_{\text {opt }}=1.752 \mathrm{~kJ} \mathrm{~d}^{-1}$ for the winter cohort) resulted in earlier sexual maturation, bringing the age at maturity forward by $5 \mathrm{~d}$ to 5.8 mo. Higher levels of food intake had little or no impact on the age of maturity (Table 3, Fig. 9c,f). Summer-hatched individuals consistently matured earlier independent of the feeding rate, reaching maturity between 45 and $205 \mathrm{~d}$ before individuals from other cohorts. 

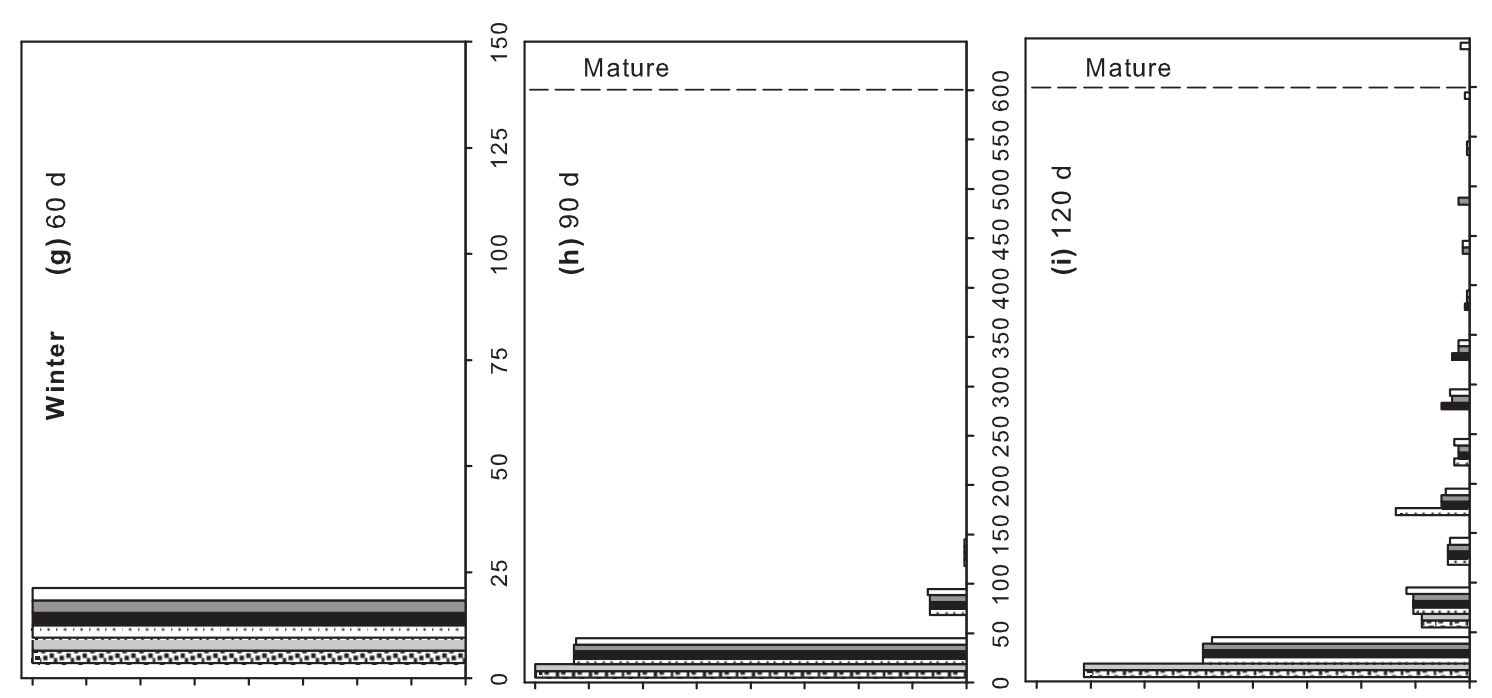

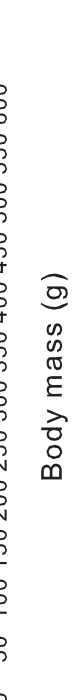

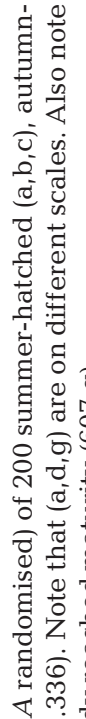
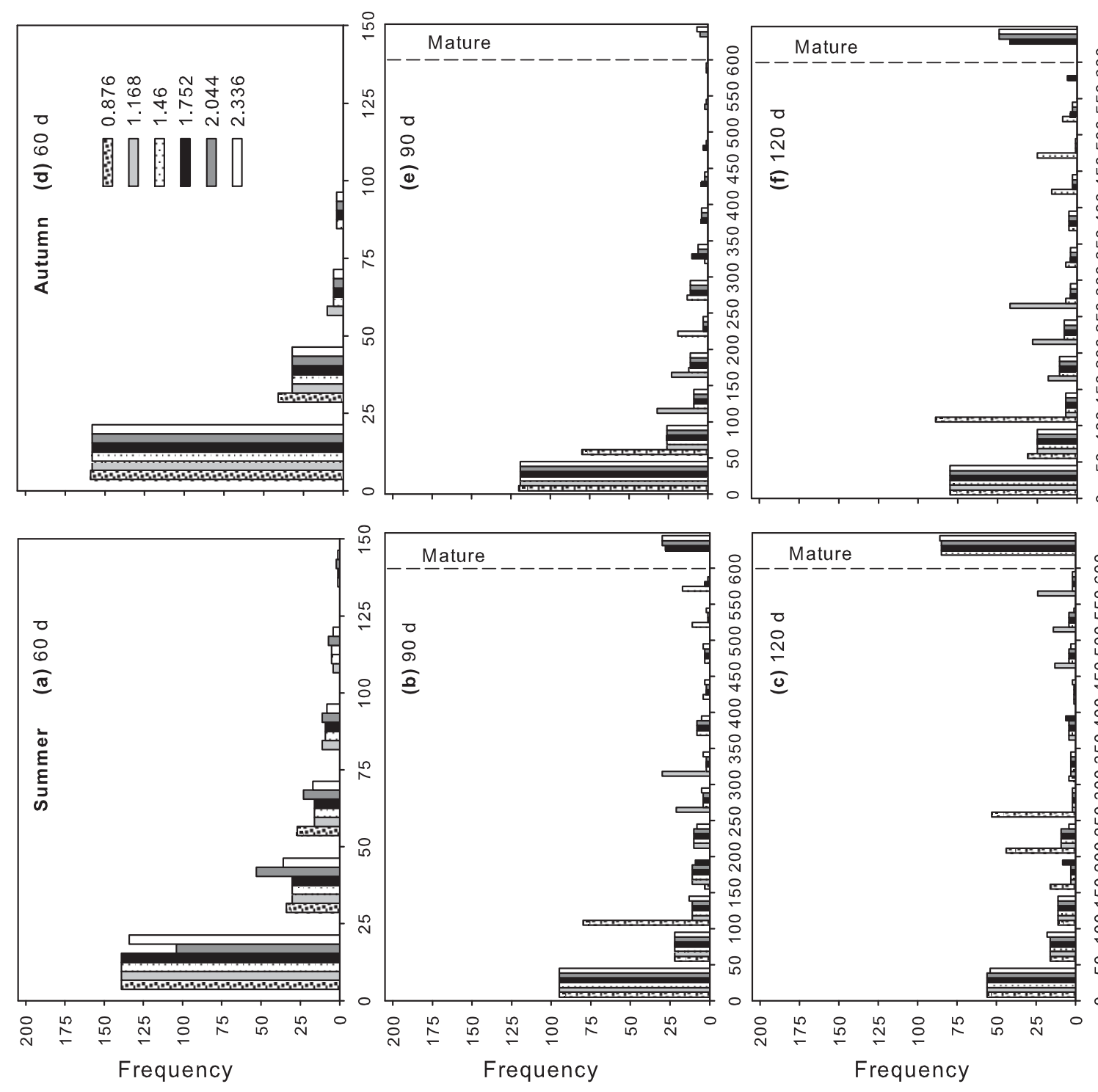

ำ

की

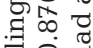

규인

웡

군

()

i 궁

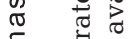

덩 흉

구 30

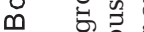

켬 윯

द्व

웅 옄

듕 ఫ

곤

륨.

규. 중

육 :

글 8

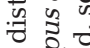

का ปี

(2) द्व

()

$\varepsilon$ ठ

ते 营坖䒕

훙

范

ปัँ

07

承 
Table 3. Octopus pallidus. Influence of food availability (expressed as $f_{\text {opt }}$ ) on the percentage of octopus displaying 2-phase growth and on the age at which $50 \%$ of the cohort reached maturity (50\% mat.) for summer-, autumnand winter-hatched cohorts. A 30 d difference in age at $50 \%$ maturity was considered significant

\begin{tabular}{|c|c|c|c|c|c|c|}
\hline \multirow{2}{*}{$\begin{array}{l}f_{\text {opt }} \\
\left(\mathrm{kJ} \mathrm{d}^{-1}\right)\end{array}$} & \multicolumn{2}{|c|}{ Summer } & \multicolumn{2}{|c|}{$\ldots$ Autumn } & \multicolumn{2}{|c|}{ Winter } \\
\hline & $\begin{array}{c}\text { 2-phase } \\
(\%)\end{array}$ & $\begin{array}{l}\text { Age } 50 \% \\
\text { mat. (d) }\end{array}$ & $\begin{array}{c}\text { 2-phase } \\
(\%)\end{array}$ & $\begin{array}{c}\text { Age } 50 \% \\
\text { mat. (d) }\end{array}$ & $\begin{array}{c}\text { 2-phase } \\
(\%)\end{array}$ & $\begin{array}{c}\text { Age } 50 \% \\
\text { mat. (d) }\end{array}$ \\
\hline 0.876 & 89 & 195 & 79.5 & 350 & 74.5 & 340 \\
\hline 1.168 & 63.5 & 135 & 65 & 210 & 59 & 340 \\
\hline 1.460 & 36 & 130 & 53 & 175 & 45 & 195 \\
\hline 1.752 & 14 & 130 & 39.5 & 175 & 30.5 & 180 \\
\hline 2.044 & 0 & 130 & 23.5 & 175 & 16.5 & 180 \\
\hline 2.336 & 0 & 130 & 12.5 & 175 & 10.5 & 180 \\
\hline
\end{tabular}

\section{DISCUSSION}

Food availability has a major impact on size-at-age and age at sexual maturity. Overall, increased food availability results in larger individuals, which is consistent with observations from laboratory experiments on octopus species including Octopus tetricus (Joll 1977), O. ocellatus (Segawa \& Nomoto 2002) and $O$. vulgaris (Villanueva et al. 2002). The present model suggests that high levels of food intake in the early life stage delays the switch to a slower growth phase, enabling individuals to grow exponentially for longer periods and reach larger sizes in a shorter time period. While this is evident for the summer and autumn cohorts, the winter cohort appears unaffected by food availability in the first 3 mo after hatching. Due to their slow growth rates as a response to low water temperatures, individuals from the winter cohort are able to maintain exponential growth for longer time periods, and only a few experienced a transition in growth phase in the first $90 \mathrm{~d}$ post-hatching. Similarly, the apparent lack of influence of food intake on size-at-age in the first 2 mo for the summer and autumn cohorts is linked to the timing of the transition in growth phase. Only very low food intake (e.g. $f_{\text {opt }}=0.876$ ) enforces a switch in growth rates in the first $60 \mathrm{~d}$ post-hatching, while other food levels lead to changes at 3 mo of age, or beyond.

High levels of food intake also resulted in earlier sexual maturation in our simulations, which is concordant with previous observations on captive octopus (Eledone moschata; Boletzky 1975) and cuttlefish (Sepia officinalis; Boletzky 1979). As the onset of sexual maturity is related to size in Octopus pallidus (Leporati et al. 2008a), individuals with high food consumption grow faster and therefore reach the body size at which sexual maturity occurs earlier, independent of the season.

Inherent growth capacities had a strong influence on size-at-age. Growth rates necessary to encompass all the variation in the wild size-at-age sample were substantially higher than growth rates obtained in captivity (Leporati et al. 2007, André et al. 2009), with an average $m_{\text {opt }}$ value for wild individuals of 0.0592 compared to 0.0167 under laboratory conditions (André et al. 2009). Captivity can alter growth in cephalopods (Joll 1977, Pecl \& Moltschaniwskyj 1999), so higher growth rates in wild individuals are likely. Alternatively, low growth rates comparable to those obtained in captivity may be characteristic of some hatchlings from natural populations, but these small, slow-growing individuals may be unlikely to recruit to the fishery due to size-selective mortality in early life history (Conover \& Schultz 1997, Steer et al. 2003) and gear selectivity of fisheries pots (minimum catch size $=250 \mathrm{~g}$ ). The observation that all the wild size-at-age data, independent of season, were encompassed within the 5th and 50th percentile range of size-at-age produced by the model results from the lack of small specimens $(<250 \mathrm{~g})$ in our dataset due to gear selectivity.

Although secondary to the effect of inherent growth capacity, variations in initial hatchling size still influenced growth. The impact of hatchling size is, however, likely to be underestimated, as the hatchling size distribution used in the present study was estimated from 1 brood only, which possibly under-represents the real range of hatchling sizes in the wild for this species.

Simulation results agreed with the Forsythe effect, i.e. during the period of decreasing temperatures, individuals grew slower, and cohorts that hatched earlier grew larger than subsequent cohorts hatched in cooler conditions. The summer cohort was overall the fastest growing cohort as a result of a combination of larger hatchling size, caused by longer incubation periods over winter and spring, and elevated water temperatures in the first months post-hatching. Autumn and winter hatchling size distributions were nearly identical due to similar incubation periods, but the autumn cohort benefited from warmer water temperatures and, hence, faster growth rates.

There has been extensive debate over the existence of a 2-phase growth pattern in wild populations of cephalopods, although this is often observed in captivity (Domain et al. 2000, Jackson \& Moltschaniwskyj 2002, Semmens et al. 2004, Arkhipkin \& Roa-Ureta 2005, Boyle \& Rodhouse 2005). Model simulations suggest that the population comprises a mixture of individuals displaying exponential growth only and 2phase growth and that the proportion of each grouping depends primarily on the individuals' inherent growth 
capacities and food availability. Low food intake and/ or high inherent growth capacity lead to an increase in the proportion of individuals displaying 2-phase growth, as animals cannot sustain exponential growth for long periods under these conditions. However, even at the lowest food consumption in our simulations, some individuals never displayed 2-phase growth and between $11 \%$ (summer cohort) and 25.5\% (winter cohort) of the individuals in each cohort maintained exponential growth throughout their immature stage. These individuals had low inherent growth capacities, which enabled them to maintain low growth rates. High food consumption $\left(1.752<f_{\text {opt }}<\right.$ $2.336 \mathrm{~kJ} \mathrm{~d}^{-1}$ ) also led to an absence of 2-phase growth in the summer cohort during the juvenile phase, with all individuals displaying exponential growth. While being the most 'successful', the summer cohort was also the most sensitive to changes in food availability, with proportionally more individuals switching from exponential only to 2-phase growth as $f_{\text {opt }}$ decreased. Considering the levels of individual variability in the factors influencing the timing of the transition between the 2 growth phases, i.e. food consumption, inherent growth capacity, and also variations in metabolic rates due to activity and specific dynamic action (which were not included in this model), it is likely that the fraction of the juvenile population displaying 2-phase growth in nature would be variable at any given time. Detecting the existence of a 2-phase growth pattern in a wild population through typical sampling would be very difficult, if not impossible, as growth curves that adequately represent the average behaviour of a population can very poorly describe the pattern followed by any individual in that population (Alford \& Jackson 1993). Detection of 2-phase growth may be achieved through an intensive mark-and-recapture program in a natural semi-enclosed area (Van Heukelem 1976). Another possibility would be to explore whether growth increments in stylets correlate with growth rate, in which case 2-phase growth could be detected for wild octopus.

The impact of maturity on the shape of individual growth curves is unclear. The additional energetic demands associated with reproduction may enforce the shift to a slower growth phase in individuals that have maintained exponential growth during their juvenile phase, and may impose further reductions in growth rates in individuals that have already shifted out of exponential growth. In any case, the progression of the size-at-age distribution in mature individuals is likely to be different from that seen in immature individuals.

The present study highlights the importance of coupling size and age data for any population study on cephalopods. Using size data alone to investigate the dynamics of wild populations could be misleading, as the size distribution of the summer and autumn cohorts tends to become bimodal with time under certain levels of food availability. While this phenomenon is in effect a consequence of the size difference between individuals that are still in exponential growth versus those that have already switched to a slower growth phase, this bimodality in size distribution could be misinterpreted as being 2 separate cohorts. This is especially relevant to octopus population studies that have traditionally used modal progression analysis on length-frequency data (Octopus mimus, Cortez et al. 1999; Eledone cirrhosa, Relini et al. 2006) for low-cost fisheries assessment, due to the lack of an aging method for these cephalopods. Recent technical developments based on stylet (an internal remnant 'shell' unique to octopus) increment analyses now allow aging in octopods (Doubleday et al. 2006, Leporati et al. 2008b), and the current study highlights the importance of accurate age estimates in future population studies.

While encompassing many factors relevant to sizeat-age in wild populations, the simulations presented here are still simplistic compared to situations in nature. Larger sample sizes would provide a better estimation of individual variability in the wild and, together with improvements to the metabolic rate term (with inclusion of the energy expended in movement and in post-prandial activity), would produce more precise growth predictions at the individual level. The assumption of constant food consumption independent of seasons may not be accurate either, as food quality and quantity are known to fluctuate seasonally. However, cephalopods are generalists that appear unselective in their choice of prey (Mather 1993, Boyle \& Rodhouse 2005) and are, therefore, likely to find sufficient food all year round, although periods of lower food availability might involve an increase in the energy expended in foraging activities. The simulations nevertheless provide some new insights into growth processes in wild benthic octopus. The shape of the growth curve (and hence size-at-age) is not only strongly influenced by seasonal temperatures during the early post-hatch phase, but also by seasonal temperatures during incubation. While the later may not be as relevant to species with short incubation periods, such as many squid species or merobenthic octopus species (producing 1000s of planktonic hatchlings, e.g. Octopus vulgaris), seasonal temperatures during incubation can result in large differences in size at hatching for species with incubation extending over the time frame of a season (e.g. O. pallidus). In the context of the predicted warming of the oceans, we can expect some significant changes in the seasonal size-at-age distribution of many octopus species. Shorter incubation periods due to higher water temperatures, com- 
bined with changes in temperature regimes posthatching and increased variation in food availability, could lead to modifications of the population structure and possibly a change in reproduction strategy, for example shifting from a year round reproductive pattern to a more seasonal pattern.

As for many cephalopod species, the lack of information on early life stages is problematic when attempting to model their life cycle. In order to refine our understanding of population structure and dynamics, future studies should focus on obtaining size-at-age information for individuals prior to their recruitment to the fishery (i.e. $<250 \mathrm{~g}$ for Octopus pallidus), as well as specific information on hatchling size distribution, which is critically lacking for cephalopod species.

Cephalopod population dynamics are complex due to the short life spans and fast responses to environmental conditions of these highly plastic animals. The present study has shown the relative influences of the combined, and sometimes counteractive, biotic and abiotic factors on cephalopod growth. Quantifying inherent growth plasticity in octopus is possible, and any reasonable attempt to model population dynamics in these species should include in some form or another seasonal temperatures, food availability and individual variations.

Acknowledgements. We are grateful to P. Ziegler for his time and technical assistance. Sample collection and experiments complied with current Tasmanian and Australian laws and were approved by the Animal Ethics Committee of the University of Tasmania under Project Nos. A0008385 and A0008130.

\section{LITERATURE CITED}

Alford RA, Jackson GD (1993) Do cephalopods and larvae of other taxa grow asymptotically? Am Nat 141:717-728

André J, Grist EPM, Semmens JM, Pecl GT, Segawa S (2009) Impact of temperature on energetics and the growth pattern of benthic octopuses. Mar Ecol Prog Ser 374:167-179

Arkhipkin AI, Roa-Ureta R (2005) Identification of ontogenetic growth models for squid. Mar Freshw Res 56: 371-386

Bartsch J (2002) Modelling the temperature mediation of growth in larval fish. Fish Oceanogr 11:310-314

Boletzky S (1975) Le developement d'Eledone moschata (Mollusca, Cephalopoda) élevée au laboratoire. Bull Soc Zool Fr 100:361-367

Boletzky S (1979) Growth and life-span of Sepia officinalis under artificial conditions (Mollusca, Cephalopoda). Rapp P-V Reun Comm Int Explor Sci Mer Mediterr 25/26: 159-168

Boletzky S (1994) Embryonic development of cephalopods at low temperature. Antarct Sci 6:139-142

Boyle P, Rodhouse PG (2005) Cephalopods ecology and fisheries. Blackwell Science, Oxford

Boyle PR, von Boletzky S (1996) Cephalopod populations: definition and dynamics. Philos Trans R Soc Lond B Biol Sci 351:985-1002
Buresch KM, Hanlon RT, Maxwell MR, Ring S (2001) Microsatellite DNA markers indicate a high frequency of multiple paternity within individual field-collected egg capsules of the squid Loligo pealeii. Mar Ecol Prog Ser 210:161-165

Caddy JF (1983) Advances in assessment of world cephalopod resources. Food and Agriculture Organization of the United Nations, Rome

Challier L, Orr P, Robin JP (2006) Introducing inter-individual growth variability in the assessment of a cephalopod population: application to the English Channel squid Loligo forbesi. Oecologia 150:17-28

Conover DO, Schultz ET (1997) Natural selection and evolution of growth rate in early life history: What are the tradeoffs? In: Chambers RC, Trippel EA (eds) Early life history and recruitment in fish populations. Chapman \& Hall, London, p 305-332

> Cortez T, González AF, Guerra A (1999) Growth of Octopus mimus (Cephalopoda, Octopodidae) in wild populations. Fish Res 42:31-39

> Domain F, Jouffre D, Caverivière A (2000) Growth of Octopus vulgaris from tagging in Senegalese waters. J Mar Biol Assoc UK 80:699-705

Domingues P, Kingston T, Sykes A, Andrade J (2001) Growth of young cuttlefish, Sepia officinalis (Linnaeus, 1758) at the upper end of the biological distribution temperature range. Aquacult Res 32:923-930

Doubleday ZA, Semmens JM, Pecl GT, Jackson GD (2006) Assessing the validity of stylets as ageing tools in Octopus pallidus. J Exp Mar Biol Ecol 338:35-42

Emery AM, Noble LR, Boyle PR (2001) Squid family values: multiple paternity of Loligo forbesi egg strings examined. Bull Mar Sci 71:1119

Forsythe JW (1993) A working hypothesis of how seasonal temperature change may impact the field growth of young cephalopods. In: Okutani T, O'Dor RK, Kubodera T (eds) Recent advances in fisheries biology. Tokai University Press, Tokyo, p 133-143

- Forsythe JW (2004) Accounting for the effect of temperature on squid growth in nature: from hypothesis to practice. Mar Freshw Res 55:331-339

Forsythe JW, Hanlon RT (1985) Aspects of egg development, post-hatching behaviour, growth and reproductive biology of Octopus burryi Voss, 1950 (Mollusca: Cephalopoda). Vie Milieu 35:273-282

Forsythe JW, Hanlon RT (1988) Effect of temperature on laboratory growth, reproduction and life span of Octopus bimaculoides. Mar Biol 98:369-379

Forsythe JW, Van Heukelem WF (1987) Growth. In: Boyle PR (ed) Cephalopod life cycles, Vol 2. Academic Press, London, p 135-156

Forsythe JW, Walsh LS, Turk PE, Lee PG (2001) Impact of temperature on juvenile growth and age at first egg-laying of the Pacific reef squid Sepioteuthis lessoniana reared in captivity. Mar Biol 138:103-112

> García García B, Aguado Giménez F (2002) Influence of diet on ongrowing and nutrient utilization in the common octopus (Octopus vulgaris). Aquaculture 211:171-182

Grist EPM, Jackson GD (2004) Energy balance as a determinant of two-phase growth in cephalopods. Mar Freshw Res 55:395-401

- Grist EPM, Jackson GD (2007) How long would it take to become a giant squid? Rev Fish Biol Fish 17:385-399

> Gurney WSC, Veitch RA (2007) The dynamics of size-at-age variability. Bull Math Biol 69:861-885

> Hatfield EMC (2000) Do some like it hot? Temperature as a possible determinant of variability in the growth of the 
Patagonian squid, Loligo gahi (Cephalopoda: Loliginidae). Fish Res 47:27-40

Hatfield EMC, Hanlon RT, Forsythe JW, Grist EPM (2001) Laboratory testing of a growth hypothesis for juvenile squid Loligo pealeii (Cephalopoda: Loliginidae). Can J Fish Aquat Sci 58:845-857

Houlihan DF, Kelly K, Boyle PR (1998) Correlates of growth and feeding in laboratory-maintained Eledone cirrhosa (Cephalopoda: Octopoda). J Mar Biol Assoc UK 78: 919-932

Hoyle K (2002) Growth and life history of Octopus pallidus: effects of seasonal temperature change. Honours thesis, University of Tasmania, Hobart

Hughes RN, Roberts DJ (1980) Growth and reproductive rates of Littorina neritoides (L.) in North Wales. J Mar Biol Assoc UK 60:591-599

Ichii T, Mahapatra K, Sakai M, Inagake D, Okada Y (2004) Differing body size between the autumn and the winterspring cohorts of neon flying squid (Ommastrephes bartramii) related to the oceanographic regime in the North Pacific: a hypothesis. Fish Oceanogr 13:295-309

Iglesias J, Otero JJ, Moxica C, Fuentes L, Sánchez FJ (2004) The completed life cycle of the octopus (Octopus vulgaris Cuvier) under culture conditions: paralarval rearing using Artemia and zoeae, and first data on juvenile growth up to 8 months of age. Aquacult Int 12:481-487

Jackson GD, Domeier ML (2003) The effects of an extraordinary El Niño/La Niña event on the size and growth of the squid Loligo opalescens off southern California. Mar Biol 142:925-935

> Jackson GD, Moltschaniwskyj NA (2001) The influence of ration level on growth and statolith increment width of the tropical squid Sepioteuthis lessoniana (Cephalopoda: Loliginidae): an experimental approach. Mar Biol 138: 819-825

> Jackson GD, Moltschaniwskyj NA (2002) Spatial and temporal variation in growth rates and maturity in the IndoPacific squid Sepioteuthis lessoniana (Cephalopoda: Loliginidae). Mar Biol 140:747-754

> Jackson GD, Forsythe JW, Hixon RF, Hanlon RT (1997) Age, growth and maturation of Lolliguncula brevis (Cephalopoda: Loliginidae) in the northwestern Gulf of Mexico with a comparison of length-frequency vs. statolith age analysis. Can J Fish Aquat Sci 54(12):2907-2919

> Jackson GD, O'Dor RK, Andrade Y (2005) First tests of hybrid acoustic/archival tags on squid and cuttlefish. Mar Freshw Res 56:425-430

Joll LM (1977) Growth and food intake of Octopus tetricus (Mollusca: Cephalopoda) in aquaria. Aust J Mar Freshw Res 28:45-56

Katsanevakis S, Protopapas N, Miliou H, Verriopoulos G (2005) Effect of temperature on specific dynamic action in the common octopus, Octopus vulgaris (Cephalopoda). Mar Biol 146:733-738

- Koehn RK (1991) The genetics and taxonomy of species in the genus Mytilus. Aquaculture 94:125-145

> Lee PG (1994) Nutrition of cephalopods: fueling the system. Mar Freshw Behav Physiol 25:35-51

> Lefkaditou E, Politou CY, Palialexis A, Dokos J, Cosmopoulos $\mathrm{P}$, Valavanis VD (2008) Influences of environmental variability on the population structure and distribution patterns of the short-fin squid Illex coindetii (Cephalopoda: Ommastrephidae) in the eastern Ionian Sea. Hydrobiologia 612:71-90

Leporati SC, Pecl GT, Semmens JM (2007) Cephalopod hatchling growth: the effects of initial size and seasonal temperatures. Mar Biol 151:1375-1383
Leporati SC, Pecl GT, Semmens JM (2008a) Reproductive status of Octopus pallidus, and its relationship to age and size. Mar Biol 155:375-385

> Leporati SC, Semmens JM, Pecl GT (2008b) Determining the age and growth of wild octopus using stylet increment analysis. Mar Ecol Prog Ser 367:213-222

Mangold K (1983) Food, feeding and growth in cephalopods. Mem Natl Mus Victoria 44:81-93

Mangold K (1987) Reproduction. In: Boyle PR (ed) Cephalopod life cycles, Vol 2. Academic Press, London, p 157-200

Mather JA (1993) Octopuses as predators, implications for management. In: Okutani T, O'Dor RK, Kubodera T (eds) Recent advances in cephalopod fisheries biology. Tokai University Press, Tokyo, p 275-282

Naud M, Hanlon RT, Hall KC, Shaw PW, Havenhand JN (2004) Behavioural and genetic assessment of reproductive success in a spawning aggregation of the Australian giant cuttlefish, Sepia apama. Anim Behav 67:1043-1050

O'Dor RK, Wells MJ (1987) Energy and nutrient flow. In: Boyle PR (ed) Cephalopod life cycles, Vol 2. Academic Press, London, p 109-133

O'Dor RK, Aitken JP, Jackson GD (2005) Energy balance growth models: applications to cephalopods. Phuket Mar Bio Cent Res Bull 66:329-336

> Pecl GT, Moltschaniwskyj NA (1999) Somatic growth processes: how are they altered in captivity? Proc R Soc Lond B 266:1133-1139

Pecl GT, Steer MA, Hodgson KE (2004a) The role of hatchling size in generating the intrinsic size-at-age variability of cephalopods: extending the Forsythe hypothesis. Mar Freshw Res 55:387-394

> Pecl GT, Moltschaniwskyj NA, Tracey SR, Jordan AR (2004b) Inter-annual plasticity of squid life-history and population structure: ecological and management implications. Oecologia 139:515-524

Pierce GJ, Valavanis VD, Guerra A, Jereb P and others (2008) A review of cephalopod-environment interactions in European Seas. Hydrobiologia 612:49-70

> Relini LO, Mannini A, Fiorentino F, Palandri G, Relini G (2006) Biology and fishery of Eledone cirrhosa in the Ligurian Sea. Fish Res 78:72-88

Ricker WE (1979) Growth rates and models. In: Hoar WS, Randall DJ, Brett JR (eds) Fish physiology, Vol VIII. Bioenergetics and growth. Academic Press, New York, p 677-743

Sakaguchi H, Araki A, Nakazono A (2002) Factors influencing body size of hatchlings, and relationships between fecundity and body weight of female Octopus vulgaris. Bull Jpn Soc Fish Oceanogr 66:79-83

Sanchez P, Demestre M, Recasens L, Maynou F, Martin P (2008) Combining GIS and GAMs to identify potential habitats of squid Loligo vulgaris in the northwestern Mediterranean. Hydrobiologia 612:91-98

Searcy SP, Sponaugle S (2000) Variable larval growth in a coral reef fish. Mar Ecol Prog Ser 206:213-226

Segawa S (1990) Food consumption, food conversion and growth rates of the oval squid Sepioteuthis lessoniana by laboratory experiments. Nippon Suisan Gakkaishi 56: $217-222$

Segawa S (1993) Field and laboratory feeding studies of the Japanese oval squid, Sepioteuthis lessoniana. In: Okutani T, O'Dor RK, Kubodera T (eds) Recent advances in fisheries biology. Tokai University Press, Tokyo, p 499-511

Segawa S, Nomoto A (2002) Laboratory growth, feeding, oxygen consumption and ammonia excretion of Octopus ocellatus. Bull Mar Sci 71:801-813

Semmens JM, Pecl GT, Villanueva R, Jouffre D, Sobrino I, Wood JB, Rigby PR (2004) Understanding octopus growth: 
patterns, variability and physiology. Mar Freshw Res 55:367-377

Shaw PW, Boyle PR (1997) Multiple paternity within the brood of single females of Loligo forbesi (Cephalopoda: Loliginidae), demonstrated with microsatellite DNA markers. Mar Ecol Prog Ser 160:279-282

Steer MA, Pecl GT, Moltschaniwskyj NA (2003) Are bigger calamary Sepioteuthis australis hatchlings more likely to survive? A study based on statolith dimensions. Mar Ecol Prog Ser 261:175-182

Steer MA, Moltschaniwskyj NA, Nichols DS, Miller M (2004) The role of temperature and maternal ration in embryo survival: using the dumpling squid Euprymna tasmanica as a model. J Exp Mar Biol Ecol 307:73-89
Van Heukelem WF (1976) Growth, bioenergetics and lifespan of Octopus cynea and Octopus maya. $\mathrm{PhD}$, University of Hawaii, Honolulu, HI

Villanueva R (2000) Effect of temperature on statolith growth of the European squid Loligo vulgaris during early life. Mar Biol 136:449-460

Villanueva R, Koueta N, Riba J, Boucaud-Camou E (2002) Growth and proteolytic activity of Octopus vulgaris paralarvae with different food rations during first-feeding, using Artemia nauplii and compound diets. Aquaculture 205:269-286

West GB, Brown JH, Enquist BJ (1997) A general model for the origin of allometric scaling laws in biology. Science 276:122-126

Appendix 1. Calculation of body mass $(B)$ under a seasonally fluctuating temperature environment. $T$ : temperature; $m$ : growth rate coefficient; $t_{\text {hatch }}$ : hatching

day in a 365 -day year; $T_{0}$ : baseline; $T_{1}$ : amplitude; $k$ : frequency, $C$ : shift

In the dynamic temperature-dependent energy balance model (DTEBM), the individual growth rate in the first phase of growth is given by:

$$
\frac{\mathrm{d} B}{\mathrm{~d} t}=m(T(t)) B
$$

where $T(t)=T_{0}+T_{1} \cos k\left(t+t_{\text {hatch }}+c\right)$. Eq. (A1) must therefore be solved to obtain body mass as a function of individual post-hatch age $t$. Integrating left and right sides of Eq. (A1):

$$
\ln B+a=\int\left(\frac{1}{B}\right) \mathrm{d} B=\int m(T(t)) \mathrm{d} t
$$

where $a$ is a constant determined by initial hatch mass, so that after rearrangement:

$$
B(t)=A \mathrm{e}^{I(t)}
$$

where $A$ is the initial hatch mass and $I(t)=\int m(T(t)) \mathrm{d} t$.

Editorial responsibility: Hans-Heinrich Janssen, Oldendorf/Luhe, Germany
Submitted: September 23, 2008; Accepted: March 26, 2009 Proofs received from author(s): May 25, 2009 